\title{
Experimental solubility and density studies on aqueous solutions of quaternary ammonium halides, and thermodynamic modelling for melting enthalpy estimations
}

\author{
Sérgio M. Vilas-Boas a,b,c , Dinis O. Abranches ${ }^{c}$, Emanuel A. Crespo ${ }^{c}$, Olga Ferreira ${ }^{\mathrm{a}, \mathrm{b}}$, \\ João A.P. Coutinho ${ }^{c}$, Simão P. Pinho ${ }^{\mathrm{a}, \mathrm{b}, *}$ \\ a Centro de Investigação de Montanha (CIMO), Instituto Politécnico de Bragança, Campus de Santa Apolónia, 5300-253 Bragança, Portugal

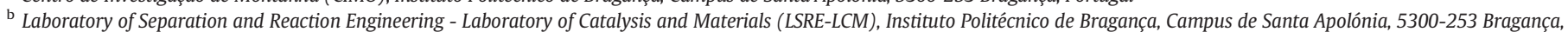 \\ Portugal \\ c CICECO - Aveiro Institute of Materials, Department of Chemistry, University of Aveiro, 3810-193 Aveiro, Portugal
}

\section{A R T I C L E I N F O}

\section{Article history:}

Received 21 November 2019

Received in revised form 3 December 2019

Accepted 6 December 2019

Available online 9 December 2019

\section{Keywords:}

Quaternary ammonium salts

Solubility

PC-SAFT

COSMO-RS

Melting

\begin{abstract}
A B S T R A C T
Aiming to extend the yet limited knowledge on phase equilibria and physical-chemical properties of quaternary alkylammonium halides and their aqueous binary systems, the solubilities of ten salts in water were measured in this work in the temperature range between $293.2 \mathrm{~K}$ and $348.2 \mathrm{~K}$ along with their densities. The PC-SAFT equation of state was then applied in the description of density as well as water activity coefficients data. The modelling results describe very satisfactorily the experimental data, and the non-associating parameters follow welldefined trends with the molecular weight of the alkylammonium halides. These parameters were applied in the prediction of the solubility data with unsatisfactory results, with mole fraction average absolute deviation $(A A D=0.018)$, deteriorating with increasing alkyl chain length. However, refitting the binary interaction parameter a much better description is obtained $(A A D=0.0045)$. COSMO-RS was also applied for the solubility prediction $(A A D=0.025)$, with poorer results for the chloride salts. After, the melting enthalpies of the quaternary alkylammonium halides were estimated using the PC-SAFT equation, which in spite of their uncertainty, are possibly the best option to perform solid-liquid equilibrium analysis of utmost importance when designing and screening new deep eutectic mixtures based on these compounds.
\end{abstract}

(c) 2019 Elsevier B.V. All rights reserved.

\section{Introduction}

Quaternary ammonium salts include a large class of cationic surfactants with a wide range of industrial applications, as ingredients in the manufacturing of softeners, emulsifiers, and several personal care products [1]. Moreover, these compounds exhibit antiseptic and disinfectant properties, being used in clinical processes and as antimicrobial agents in formulations and in the textile industry [1-3]. These compounds are also relevant as some of them are ionic liquids (ILs), and can be used to form eutectic mixtures displaying interesting physical properties [4-7]. It is surprising that so far only a few studies [8-10] on their solubility and solid state properties have been carried out, which are of relevance to improve the scientific and technical background of current applications, and developing new ones.

\footnotetext{
* Corresponding author at: Centro de Investigação de Montanha (CIMO), Instituto Politécnico de Bragança, Campus de Santa Apolónia, 5300-253 Bragança, Portugal.

E-mail address: spinho@ipb.pt (S.P. Pinho).
}

In this work, the densities of aqueous solutions of cholinium bromide $([\mathrm{Ch}] \mathrm{Br})$, cholinium chloride $([\mathrm{Ch}] \mathrm{Cl})$ and a series of eight tetraalkylammonium halides $\left(\mathrm{N}_{1111} \mathrm{X}, \mathrm{N}_{2222} \mathrm{X}, \mathrm{N}_{3333} \mathrm{X}, \mathrm{N}_{4444} \mathrm{X}\right.$, where $\mathrm{X}$ is either the chloride or the bromide anion) were measured from $293.2 \mathrm{~K}$ to $348.2 \mathrm{~K}$. In mole fraction basis, the salt concentration ranges from 0.05 to the saturation limit at $298.2 \mathrm{~K}$. Whenever possible, the obtained data were critically compared to data from the open literature. However, although several studies report density data for aqueous solutions of the selected salts [11-25], few report data on the same range of concentrations investigated in this work [7,26-30].

Additionally, the solubility of the selected salts in water was measured in the (298.2-343.2) K temperature range. To the best of our knowledge, there are no data available in literature for temperatures other than $298.2 \mathrm{~K}$, but even so the measured solubility data were compared to the reported data $[10,31,32]$.

In order to extend the impact of the new experimental data, and aiming at the industrial application of these salts, density, activity coefficients and solubility modelling was carried out. However, for 
solid-liquid equilibrium studies, calorimetric data are needed. While for the melting temperature, reliable data or estimates are available, for the enthalpy of melting or solid-solid transitions the information available is scarce, and the data are often inconsistent between different sources, due to sample thermal history or kinetic effects, or even impossible to measure due to salt decomposition. Therefore, a simplified approach has been implemented avoiding the identification of solid-solid transitions and the use of the melting enthalpy.

The complex nature of aqueous systems, ILs, or the so-called deep eutectic solvents (DES), involving these salts, strongly influenced by the presence of hydrogen bonds and other short range and highly directional forces, cannot be well described by most models including the well-known cubic EoS. Molecular-based approaches derived from the Statistical Associating Fluid Theory (SAFT) [33-36] are able to explicitly account for different structural and energetic effects (e.g. molecular shape, chain length, hydrogen bonding, polar interactions) on the physical behavior of the system and thus should be used on the description of these systems. Given the proven robustness and accuracy of SAFT-based EoS in describing a wide variety of systems including aqueous systems, ILs and DES, especially those containing quaternary ammonium halide salts [7,37,38], the experimental data measured in this work (densities and solubilities) as well as water activities were described using the Perturbed-Chain variant of SAFT (PC-SAFT) $[39,40]$. The capability of the fully predictive COSMO-RS model was also tested in the representation of the solubility.

\section{Experimental details}

\subsection{Materials}

The source, purity, water content and molar mass of the chemicals used in this work as well as their melting temperatures are given in Table 1 . In the solubility and density measurements, ultra-pure water (resistivity of $18.2 \mathrm{M} \Omega$.cm, free particles $\geq 0.22 \mu \mathrm{m}$ and total organic carbon $<5 \mu \mathrm{d} \cdot \mathrm{dm}^{-3}$ ) was used. All the organic salts were stored at room temperature and used as received from the supplier.

\subsection{Density measurements}

To perform the density measurements, binary aqueous solutions of known salt mole fraction (up to 0.3 , whenever possible) were prepared for each salt, inside a glove chamber (captair pyramid, Erlab) operating under humidity levels lower than $16 \%$. The water content of each salt was determined by Karl-Fisher titration, which was taken into consideration in the preparation of the solutions. The density measurements of the aqueous solutions were carried out using a vibrating tube densimeter (DMA $5000 \mathrm{M}$, Anton Paar) coupled to a U-shaped tube, with uncertainties within $\pm 5.10^{-5} \mathrm{~g} / \mathrm{cm}^{-3}$. The densities were measured from 293.15 to $348.15 \mathrm{~K}$ at $0.1 \mathrm{MPa}$ and a preconditioning step of the samples was required to avoid bubble formation. To do so, the solutions were taken to an ultrasonic bath (Ultrasons-H, JP Selecta S.A.) for twenty minutes, and then submerged into a thermostatic bath at $358.2 \mathrm{~K}$ for $15 \mathrm{~min}$ under slow agitation (TC120, Grant). All the measurements were preceded by a calibration step with ultra-pure water and air.

\subsection{Solubility measurements}

The solubilities were measured between $298.15 \mathrm{~K}$ and $343.15 \mathrm{~K}$, using the isothermal shake-flask method, which was described in detail by Ferreira and Pinho [44]. Saturated solutions were prepared in a flask by mixing a small amount of solid in excess with around $100 \mathrm{ml}$ of solvent. The flaks were placed over magnetic stirrers (MICRO Variomag Magnetic Stirrer, Thermo Fisher Scientific) inside a thermostatic water bath (TC120, Grant). The temperature control system ensures that the solution temperature is within $\pm 0.1 \mathrm{~K}$ to the set temperature.

Preliminary experiments showed that the adequate times of stirring and settling were lower than $15 \mathrm{~h}$ and $4 \mathrm{~h}$, respectively. After reaching the equilibrium, four samples of around $3 \mathrm{ml}$ were collected using previous heated plastic syringe coupled to polypropylene filters $(0.45 \mu \mathrm{m}$ pore diameter $)$. Then, the samples were weighted in an electronic balance (Denver Instruments, precision of $\pm 0.1 \mathrm{mg}$ ), before being quantitatively analyzed by refractometry (Abbemat 500, Anton Paar) with a reproducibility within $\pm 5.10^{-5}$. For each of the four collected samples, at least three independent measurements were performed.

\section{Computational details}

\subsection{Thermodynamic framework}

The solid-liquid equilibrium curve of a generic component $\boldsymbol{i}$ that solidifies into a pure form from a mixture is described as follow [45]:

$$
\ln \left(x_{i} \cdot \gamma_{i}\right)=\frac{\Delta_{m} h_{i}}{R} \cdot\left(\frac{1}{T_{m, i}}-\frac{1}{T}\right)+\frac{\Delta_{m} C p_{i}}{R} \cdot\left(\frac{T_{m, i}}{T}-\ln \frac{T_{m, i}}{T}-1\right)
$$

where $x_{i}$ is the mole fraction of the component $i$ in the liquid phase, $\gamma_{i}$ its activity coefficient, $\Delta_{m} h_{i}$ its melting enthalpy, $T_{m, i}$ its melting temperature and $\Delta_{m} C p_{i}$ its heat capacity change upon melting, while $T$ is the absolute temperature of the system and $R$ is the ideal gas constant. Since the $\Delta_{m} C p_{i}$ term is not available in the literature

Table 1

Purity (\%), source, water content, molar mass and melting temperature of the salts used in this work.

\begin{tabular}{|c|c|c|c|c|c|}
\hline Component & Purity (\%) ${ }^{\mathrm{a}}$ & Supplier & Water content $^{\mathrm{b}}$ & Molar mass $(\mathrm{g} / \mathrm{mol})^{\mathrm{c}}$ & $T_{m}(\mathrm{~K})$ \\
\hline$\left[\mathrm{N}_{1111}\right] \mathrm{Br}$ & $\geq 98$ & Alfa Aesar & $0.01 \%$ & 154.049 & $645.65^{d}$ \\
\hline$\left[\mathrm{N}_{2222}\right] \mathrm{Br}$ & $\geq 98$ & Alfa Aesar & $0.47 \%$ & 210.155 & $568.25^{\mathrm{e}}$ \\
\hline$\left[\mathrm{N}_{3333}\right] \mathrm{Br}$ & $\geq 98$ & Alfa Aesar & $0.06 \%$ & 266.261 & $535.15^{\mathrm{e}}$ \\
\hline$\left[\mathrm{N}_{4444}\right] \mathrm{Br}$ & $\geq 98$ & Alfa Aesar & $0.29 \%$ & 322.368 & $376.26^{\mathrm{e}}$ \\
\hline$\left[\mathrm{N}_{1111}\right] \mathrm{Cl}$ & $\geq 98$ & $\mathrm{TCI}$ & $0.24 \%$ & 109.598 & 612.87 [7] \\
\hline$\left[\mathrm{N}_{2222}\right] \mathrm{Cl}$ & $\geq 98$ & Alfa Aesar & $2.39 \%$ & 165.704 & $535.40[41]$ \\
\hline$\left[\mathrm{N}_{3333}\right] \mathrm{Cl}$ & $\geq 99$ & Alfa Aesar & $0.26 \%$ & 221.810 & $503.07[7]$ \\
\hline$\left[\mathrm{N}_{4444}\right] \mathrm{Cl}$ & $\geq 98$ & Aldrich & $0.31 \%$ & 277.917 & $342.82^{\mathrm{e}}$ \\
\hline$[\mathrm{Ch}] \mathrm{Br}$ & $\geq 98$ & $\mathrm{TCI}$ & $0.06 \%$ & 184.075 & $581.60[41]$ \\
\hline$[\mathrm{Ch}] \mathrm{Cl}$ & $\geq 99$ & Acros & $0.20 \%$ & 139.624 & $597.00[42]$ \\
\hline
\end{tabular}

a All the mentioned mass purities were guaranteed by the manufacturer.

b Mass percentage of water measured by Karl-Fisher titration (Metrohm, 831 KF Coulometer).

c The molar masses were taken from ChemSpider [43].

d This value was estimated comparing the melting temperature differences between the chloride and bromide salts.

e Unpublished data. 
for the substances herein studied, mostly due to the difficulty of its measurement and decomposition upon melting, and also its contribution to Eq. (1) is usually negligible, the solid-liquid curve of component $i$ may be approximated to [46,47]:

$$
\ln \left(x_{i} \cdot \gamma_{i}\right)=\frac{\Delta_{m} h_{i}}{R} \cdot\left(\frac{1}{T_{m, i}}-\frac{1}{T}\right)
$$

Eq. (2) could be applied to model and describe the solubility results reported in this work. However, some of the compounds decompose upon melting and their melting enthalpies are not available nor can be directly measured. Nevertheless, modelling of the solubility data is still possible through the introduction of a reference condition:

$$
\frac{\ln \left(x_{i} \cdot \gamma_{i}\right)}{\ln \left(x_{i, R e f} \cdot \gamma_{i, R e f}\right)}=\frac{\frac{\Delta_{m} h_{i}}{R} \cdot\left(\frac{1}{T_{m, i}}-\frac{1}{T}\right)}{\frac{\Delta_{m} h_{i}}{R} \cdot\left(\frac{1}{T_{m, i}}-\frac{1}{T_{R e f}}\right)}
$$

where $x_{i, \text { Ref }}$ is the mole fraction solubility of component $i$ at the reference temperature, $\gamma_{i, \text { Ref }}$ its activity coefficient and $T_{\text {Ref }}$ the temperature of the reference condition. Rearranging and simplifying Eq. (3), the final modelling expression is obtained:

$$
\ln \left(x_{i} \cdot \gamma_{i}\right)=\frac{T-T_{m}}{T_{R e f}-T_{m}} \cdot \frac{T_{R e f}}{T} \cdot \ln \left(x_{i, R e f} \cdot \gamma_{i, R e f}\right)
$$

In this work, the reference state was chosen to be the experimental solubility of the target compound in water at $298 \mathrm{~K}$, except otherwise noted. The reference activity coefficient is then estimated using PCSAFT or COSMO-RS at that temperature and experimental composition. Finally, the whole solubility curve is calculated as per Eq. (4) using the studied models.

\subsection{PC-SAFT}

Over the last decades, the increasing complexity of the systems of interest to the chemical industry have highlighted the limitations of well-known and widely applied cubic EoSs such as Peng-Robinson or Soave-Redlich-Kwong, especially when those are applied to describe highly polar and asymmetrical fluids or systems where anisotropic associative or electrostatic interactions play a key role, demanding the development and application of reliable and accurate thermodynamic models that could be used for a broader range of applications.

The most important progress towards EoSs with such capabilities was achieved by molecular-based EoSs, derived from statistical mechanics concepts, that can explicitly account for different effects that the molecular structure and its non-spherical shape or the existence of different types of interactions have on the thermodynamic behavior of a fluid. An example of such approach is the SAFT-EoS, developed by Chapman and co-workers [33-36] based on the first-order thermodynamic perturbation theory (TPT1) proposed by Wertheim [48-51]. Within the framework of SAFT, molecules are represented as a chainlike fluid where a number of equally-sized spherical monomers are covalently bonded to each other. Additionally, these chains may or may not contain specific short-range bonding sites to model associative interactions.

SAFT provides an expression for the residual Helmholtz energy of the system, $A^{r e s}$, as a sum of different contributions according to Eq. (5):

$\frac{A^{\text {res }}}{N k_{B} T}=\frac{A^{\text {mon }}}{N k_{B} T}+\frac{A^{\text {chain }}}{N k_{B} T}+\frac{A^{\text {assoc }}}{N k_{B} T}$ where, $A^{\text {mon }}$ represents the contribution due to the monomermonomer interactions (either attractive or repulsive), $A^{\text {chain }}$ the contribution due to the covalent bonds between monomers forming a chain from the individual segments, and $A^{a s s o c}$ is the contribution due to the existence of short-range and highly directional forces. The summation form of Eq. (5) allows SAFT to be easily extended, depending on the systems nature, through the inclusion of additional terms, e.g. the inclusion of a polar term to explicitly account for polar and multipolar interactions in systems where those interactions play a key role such as those containing polar gases or aromatic compounds.

PC-SAFT $[39,40]$ is one of the most popular variants of SAFT. Contrarily to most other SAFT variants, instead of hard-spheres as a reference fluid it considers a hard-chain reference fluid, $A^{h c}$, consisting on $m_{i}$ freely jointed monomers (exhibiting repulsive interactions) that accounts for the shape and length of molecules, while the dispersive interactions are considered in a separate term, $A^{\text {disp }}$. Therefore, Eq. (5) can be rewritten for the particular case of PC-SAFT as:

$\frac{A^{r e s}}{N k_{B} T}=\frac{A^{h c}}{N k_{B} T}+\frac{A^{\text {disp }}}{N k_{B} T}+\frac{A^{a s s o c}}{N k_{B} T}$

The expression for $A^{\text {disp }}$ is obtained from the perturbation theory of Barker and Henderson [52,53] and introduces two additional pure-component parameters in the model: the monomer's diameter, $\sigma_{i i}$ and the dispersive energy characterizing the attractive interactions between individual monomers, $u_{i i} / k_{B}$. These two parameters along with the chain length parameter $m_{i}$ fully characterize a nonassociating component in the framework of PC-SAFT. To apply the model to mixtures, the van der Waals one fluid theory is employed using the mixing rules below to obtain the cross-interaction parameters:

$\sigma_{i j}=\frac{\sigma_{i i}+\sigma_{j j}}{2}$

$u_{i j}=\left(1-k_{i j}\right) \sqrt{u_{i i} u_{j j}}$

To account for deviations from the behavior predicted by the Lorentz-Berthelot mixing rules, a binary interaction parameter, $k_{i j}$, correcting the mixtures dispersive energy, may be introduced to improve agreement with the experimental data.

The association term, particularly relevant for the accurate modelling of salts, ILs and DES given the relevance of anisotropic interactions in these systems, requires two additional parameters, namely the energy $\left(\varepsilon_{i i}^{H B}\right)$ and volume $\left(\kappa_{i i}^{H B}\right)$ characterizing the square-well bonding sites. If more than one self-associating component is present, as it is the case for the aqueous solutions investigated in this work, crossassociation parameters are required, those being obtained from the self-associating parameters through the Wolbach and Sandler [54] combining rules:

$\varepsilon_{i j}^{H B}=\frac{\varepsilon_{i i}^{H B}+\varepsilon_{j j}^{H B}}{2}$

$\kappa_{i j}^{H B}=\sqrt{\kappa_{i i}^{H B} \kappa_{j j}^{H B}}\left(\frac{\sqrt{\sigma_{i i} \sigma_{j j}}}{1 / 2\left(\sigma_{i i}+\sigma_{j j}\right)}\right)^{3}$

Further details about the expressions required to the evaluation of the different terms of Eq. (6) are outside the scope of this work but can be found in the original publications by Gross and Sadowski $[39,40]$. The PC-SAFT calculations carried in this work were performed using the software Multiflash 7.0 by KBC-Infochem. The coarsegrained models and pure-component parameters considered are presented in the next section. 


\subsection{PC-SAFT coarse-grained models}

The consistency and accuracy of the results obtained with SAFT-type EoSs rely on the careful development of appropriate coarse-grained models able to adequately describe the physical behavior of the molecules. These include not only a proper fitting of the five purecomponent parameters defined in the previous section but also the definition of a suitable association scheme for each molecule. The so-called association scheme defines the number and type of association sites present in the molecule and how those sites are allowed to interact in the system (both self and cross-associating interactions need to be specified).

Water is modelled using a 2-site model as proposed by Cameretti and Sadowski [55]. This model contains a temperature-dependent segment diameter that ensures a good description of the solvent in a wide range of temperatures by the EoS.

Several authors have reported the use of PC-SAFT to model aqueous solutions of ionic liquids and salts, including some of the quaternary ammonium chlorides studied in this work [7,37,56-58]. All of these authors have treated the different salts as associating species by considering the $2 \mathrm{~B}$ association scheme, according to the nomenclature proposed by Huang and Radosz [59], where to each salt two association sites of different nature, one site of type "A" and one site of type "B" are assigned to mimic the cation-anion interactions with " $\mathrm{AB}$ " interactions being allowed in the system. This association scheme is illustrated in Fig. 1 for $\left[\mathrm{N}_{2222}\right] \mathrm{Cl}$.

In this work, the 2B association scheme is also applied to the modelling of the symmetrical tetraalkylammonium halides but, contrarily to the work of Zubeir et al. [37], where a CG model for [Ch]Cl was also proposed based on the $2 \mathrm{~B}$ association scheme, the cholinium-based salts are here modelled with an additional pair of association sites to explicitly account for the presence of the hydroxyl group. Hence cholinium-based salts ([Ch]Cl and $[\mathrm{Ch}] \mathrm{Br})$ are modelled using two positive sites, representing delocalized charge of the cation and the hydrogen atom of the hydroxyl group, and two negative association sites, representing the anion and the lone electron pairs on the oxygen atom. Although PC-SAFT parameters were already available for $\left[\mathrm{N}_{1111}\right] \mathrm{Cl},\left[\mathrm{N}_{2222}\right] \mathrm{Cl},\left[\mathrm{N}_{3333}\right] \mathrm{Cl}$, and $\left[\mathrm{N}_{4444}\right]$ $\mathrm{Cl}$ from the works of Zubeir et al. [37] and Pontes et al. [7], they were also refitted in this work as the parameters available in literature do not obey the trends usually observed in SAFT parameters within a homologous series, i.e. $m_{i}, m_{i} \sigma_{i i}^{3}$, and $m_{i} u_{i i} / k_{B}$ vary linearly with the molecular weight [60-62].

Concerning the parameterization procedure, pure-component parameters for SAFT models are typically obtained by fitting vaporliquid equilibrium (VLE) data for the pure fluid, namely the vapor pressures and saturated liquid densities. However, due to the high melting points of quaternary ammonium salts such data are not available and alternative parameterizations are required. Llovell

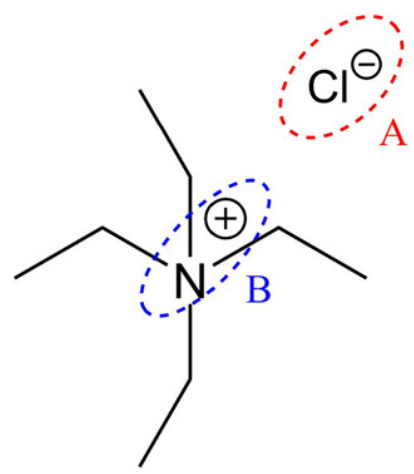

Fig. 1. Association scheme for the symmetrical tetraalkylammonium halides. and co-workers $[38,63]$ suggested the use of density data of mixtures of salt with glycols or carboxylic acids to obtain the soft-SAFT parameters while Zubeir et al. [37] and Pontes et al. [7] have suggested the use of aqueous solutions data to obtain the PC-SAFT parameters, namely densities at different salt concentrations along with osmotic coefficients or water activity coefficients data. Since aqueous systems are very challenging to model and often require the simultaneous fitting of a binary interaction parameter to achieve a reasonable agreement with the experimental data, we opted by following this latter approach as we consider that using only density data may hinder the model to capture energy-related features of the molecules. Hence, we regressed the molecular parameters for the 10 different salts using the density data measured in this work and the water activity coefficients data by Khan et al. [64] or those obtained from the osmotic coefficients reported by Lindenbaum and Boyd [8]. For cholinium bromide, as no water activity coefficient data were available, only the density data measured in this work were used to regress the salt parameters, but care was taken to ensure the physical meaning of the parameters.

\subsection{COSMO-RS}

COSMO-RS, short for Conductor like Screening Model for Real Solvents, is a quantum chemistry-based model that predicts the chemical potential of all components in a liquid mixture solely through ab initio calculations of the pure compounds [65,66]. To do so, COSMO-RS divides the sigma surface of each molecule into specific area segments and, then, considers pair-wise interactions between the segments of each molecule in the liquid mixture to estimate the chemical potential of a compound in a mixture. Since the activity coefficient is calculated from the chemical potential, this model can be used along with Eq. (4) to estimate the solubility curve of a target compound in water.

To optimize the geometries of each molecule and calculate the corresponding sigma surface, the software TmoleX (interface for TURBOMOLE) was used $[67,68]$. Specifically, the COSMO-BP-TZVP template was employed, which includes a def-TZVP basis set, a DFT with the B-P86 functional and the COSMO solvation model (continuum solvent with infinite permittivity). In line with previous studies $[69,70]$, and due to a shortcoming in the model regarding electrolyte species [71], all salts were optimized as neutral ionic pairs instead of separate cation and anion species. Finally, the COSMO-RS model was applied through the software COSMOtherm [72,73] using the BP_TZVP_C30_1701 parametrization.

\section{Results and discussion}

\subsection{Experimental densities}

A complete overview of the measured densities as well as the data found in literature is given in Tables S1-S10 of Supporting Information. Whenever possible, the density measured in this work was compared to experimental data found in literature, and the results are shown in Figs. S1-S3 of Supporting Information. Generally, a good agreement was found with the few data available in the literature, and to the best of our knowledge, the densities of aqueous solutions of $\left[\mathrm{N}_{2222}\right] \mathrm{Br}$, [Ch] Br or $\left[\mathrm{N}_{4444}\right] \mathrm{Cl}$ are reported for the first time in the mole fraction of salt and temperature ranges studied in this work.

For all aqueous systems, densities decrease as the temperature increases, but concerning salt concentration, while solution molar density (in $\mathrm{mol} / \mathrm{L}$ ) decreases as the salt mole fraction increases for all studied systems, the volumetric mass $\left(\mathrm{kg} / \mathrm{m}^{3}\right)$ decreases only for aqueous solutions of $\left[\mathrm{N}_{3333}\right] \mathrm{Cl}$ or $\left[\mathrm{N}_{4444}\right] \mathrm{Cl}$. 
Table 2

Solubility measurements of $\left[\mathrm{N}_{2222}\right] \mathrm{Cl}$ in water from $308.15 \mathrm{~K}$ to $313.15 \mathrm{~K}$.

\begin{tabular}{lll}
\hline Temperature $(\mathrm{K})$ & Solubility $(\mathrm{g} / \mathrm{g}$ of solvent) & $x_{\text {Salt }}$ \\
\hline 304.15 & $1.895 \pm 0.002$ & 0.1708 \\
305.15 & $2.103 \pm 0.002$ & 0.1861 \\
306.15 & $2.164 \pm 0.001$ & 0.1905 \\
306.65 & $3.004 \pm 0.004$ & 0.2462 \\
307.15 & $3.023 \pm 0.002$ & 0.2474 \\
\hline
\end{tabular}

\subsection{Experimental solubilities}

The solubilities in water of the salts studied in this work (298.2-343.2) K are presented in Tables S11 and S12 of Supporting Information. Excepting tetraethylammonium halides salts at lower temperatures, all alkyl ammonium chlorides present higher solubilities in water than bromides, following the general trend that melting temperatures are lower in chlorides as well as the water activity coefficients, showing that water preferably interact with chlorides than bromides, as demonstrated in the review by Collins et al. [74] . Concerning the two choline salts, the solubility of the chloride is also higher than the solubility of the bromide, and generally those are larger than the corresponding solubilities of the alkylammonium halides, which can be related to the presence of the polar hydroxyl group in the cation.

A point deserving also attention is that the solubilities of [ $\left.\mathrm{N}_{4444}\right] \mathrm{Cl}$ and $\left[\mathrm{N}_{4444}\right] \mathrm{Br}$ are considerably higher than the solubilities of the other alkylammonium salts with the same anions. This is related to the fact that the tetrabutylammonium salts present much lower melting temperatures than the other salts. Moreover, the solubility change with temperature, related with the enthalpy of melting of these compounds, is quite impressive, in particular for the solubility of $\mathrm{N}_{4444} \mathrm{Cl}$ in water.

In the case of the tetraethylammonium chloride, another peculiar behavior is observed: the solubility doubles from 298.15 to $308.15 \mathrm{~K}$, while a much smaller solubility increase with the temperature is
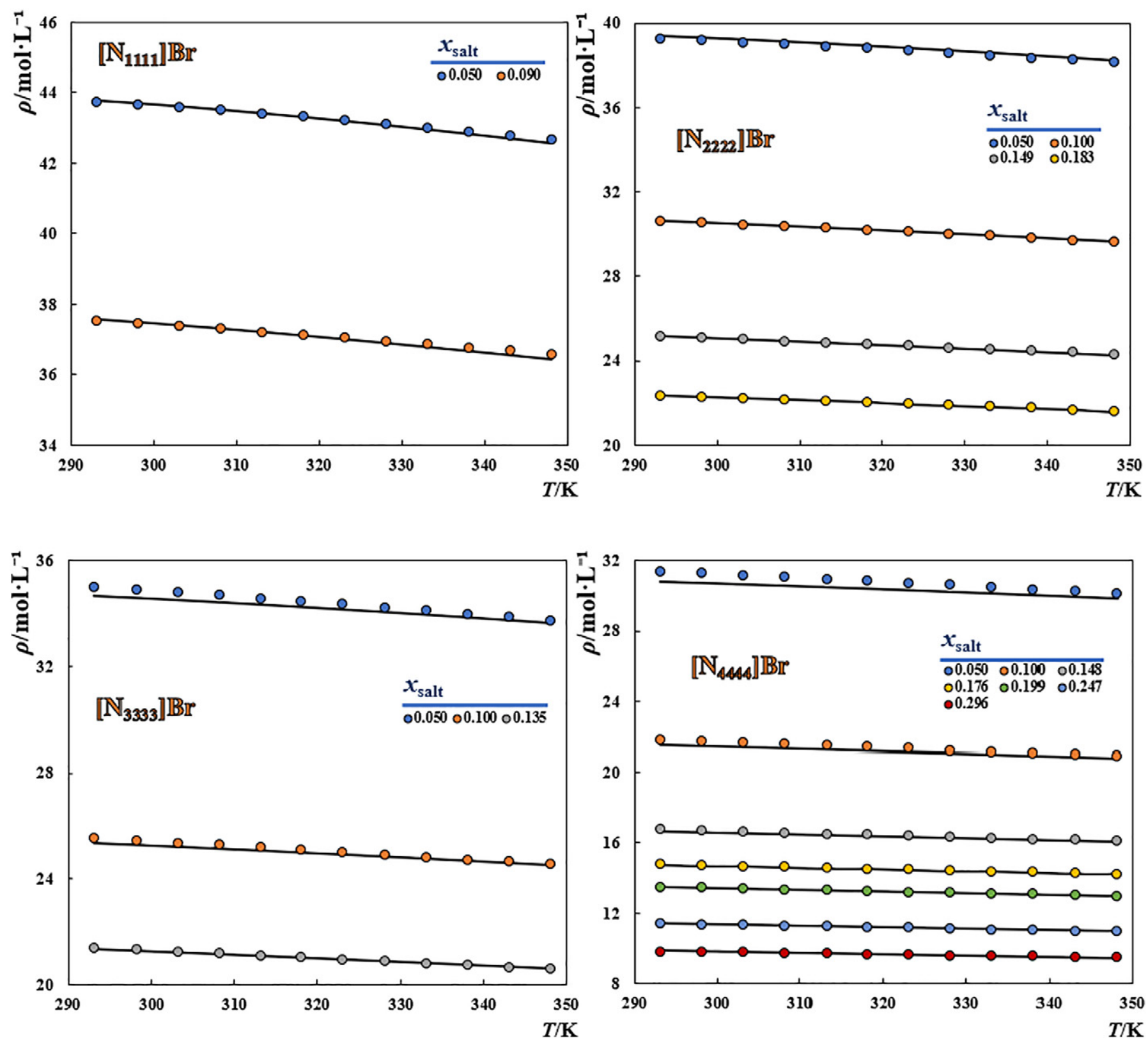

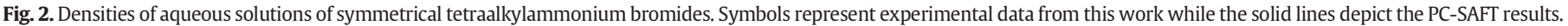


observed above $308.15 \mathrm{~K}$. For this reason, additional solubility measurements were performed to investigate the SLE of the system $\left[\mathrm{N}_{2222}\right] \mathrm{Cl}+$ water from 308.15 to $313.15 \mathrm{~K}$. The results are presented in Table 2, indicating that $\left[\mathrm{N}_{2222}\right] \mathrm{Cl}$ crystalline form, in presence of water changes, in the temperature interval between $306.15 \mathrm{~K}$ and $306.65 \mathrm{~K}$.

To the best of our knowledge, only solubility data at $298.2 \mathrm{~K}$ is available in literature for the systems studied here. In Table S13 of Supporting Information, a comparison of the data found in literature with the data obtained in this work is presented.

In the case of the tetraalkylammonium bromides, the data obtained in this work are in good agreement with the values reported by Nakayama [10], Levien [31] and Burns and Furter [32] presenting average relative deviation (ARD) lower than 5.4\%. For the chlorides, data from this work are quite comparable with the data published in literature [10], being $\left[\mathrm{N}_{2222}\right] \mathrm{Cl}$ the one presenting the lowest ARD $(0.8 \%)$ and $\left[\mathrm{N}_{1111}\right] \mathrm{Cl}$ presenting the highest ARD (14.1\%). For the two choline-based salts, no solubility data were found in the literature.

\subsection{Modelling}

The results of the fittings concerning density and activity coefficient data are illustrated in Figs. 2-6, while the resulting PC-SAFT parameters are reported in Table 3 along with the absolute ARD deviations. As can be observed in Fig. 2 to Fig. 4, a good description of the densities of the aqueous solutions of the different salts were obtained with absolute percentage ARD (\%AARD) ranging from as low as $0.125 \%$ to a maximum of $0.545 \%$. The deviations were found to decrease with increasing salt concentrations, explaining why the highest deviations are observed for the aqueous solutions of [ $\mathrm{N}_{4444}$ ] $\mathrm{Cl}$ for which densities were measured for solutions with salt mole fractions as low as 0.039 .

Concerning the activity coefficients of water an overall good description of the experimental data was achieved for all systems with exception of [ $\left.\mathrm{N}_{4444}\right] \mathrm{Br}$ for which the experimental data exhibited a distinct trend, much different than those observed for the remaining salts, as can be observed in Fig. S4. This experimental trend could not be captured, not even qualitatively, by the PC-SAFT
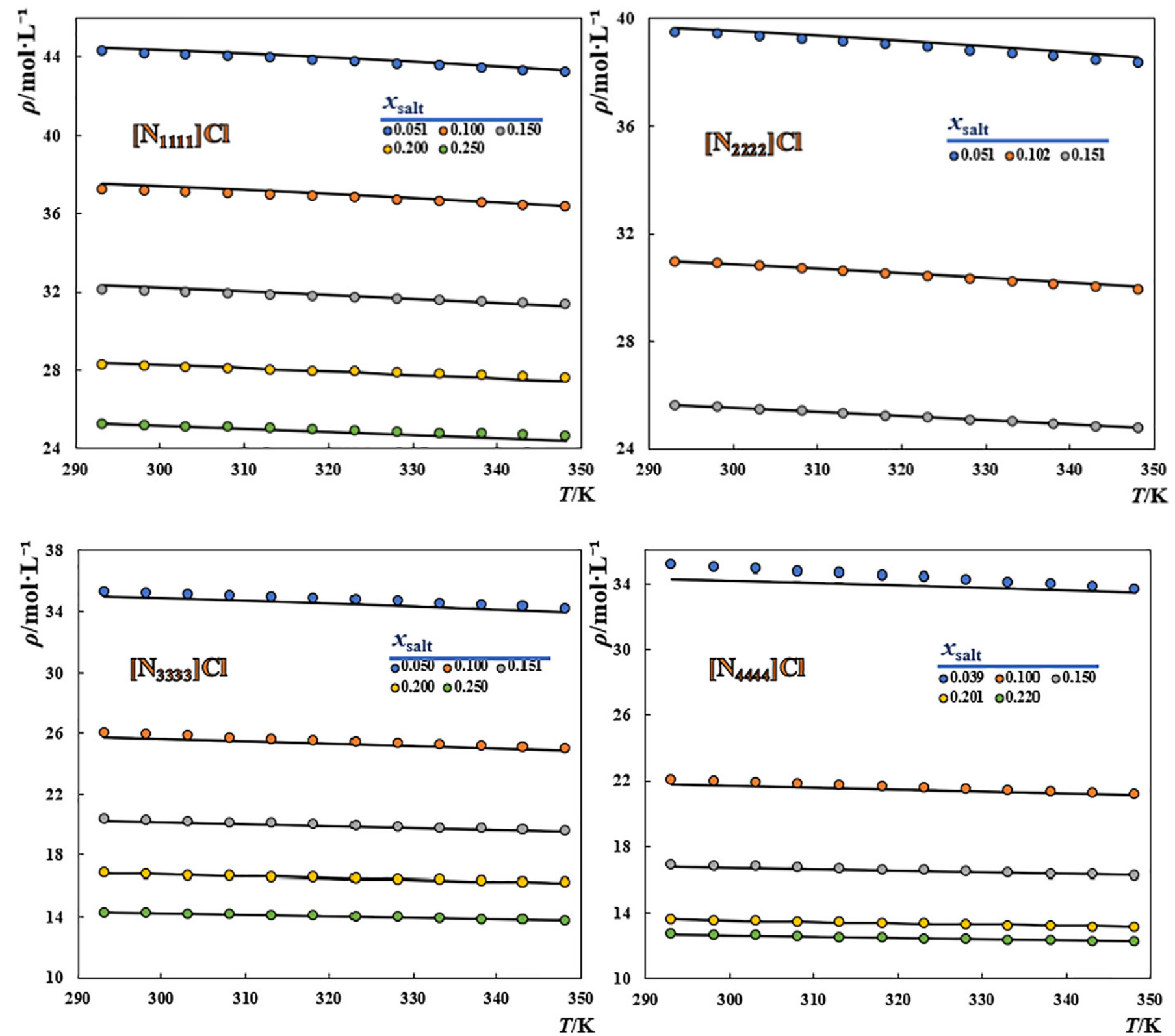

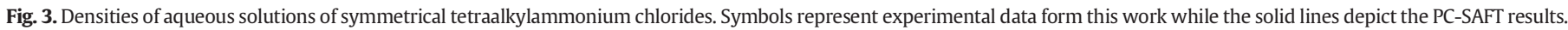



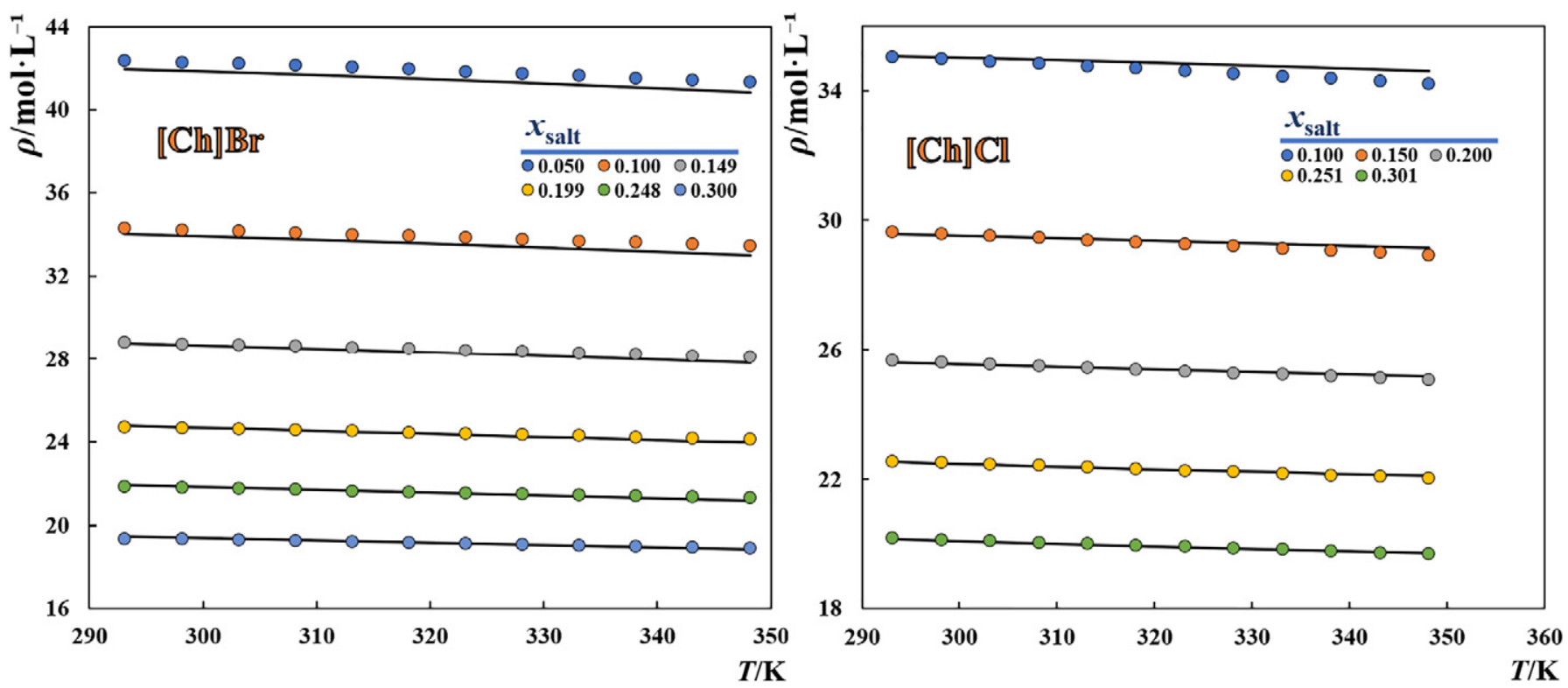

Fig. 4. Densities of aqueous solutions of cholinium-based salts. Symbols represent experimental data from this work while the solid lines depict the PC-SAFT results.

model. Deviations are also observed in some other systems as the salt concentration is increased, and a change in the concavity of the curve is observed, as it is the case of $\left[\mathrm{N}_{3333}\right] \mathrm{Cl}$. For this system, although deviations start to increase for water mole fractions $<0.85$, PC-SAFT can capture the change in the shape of the curve.

As mentioned before, one of the advantages of SAFT-type EoSs is the enhanced physical meaning of the model parameters and its consequent improved transferability. Hence, for a homologous series of compounds where only small structural changes (e.g. chain length) are present, as it is the case of the tetraalkylammonium halide salts investigated in this work, the non-associating parameters are expected to follow well-defined trends with the molecular weight. These trends are exhibited in Fig. 7 and could be used to provide reasonable estimates of the PC-SAFT parameters for similar salts with different chain length without further fitting. To the best of our knowledge this is the first set of parameters proposed for tetraalkylammonium salts in the framework of a SAFT-type EoS where all the expected trends for the non-associating parameters are observed.

Concerning the associating parameters, the association volume could be kept fixed for the different salts without decreasing the model accuracy while the association energy was found to increase from the symmetrical tetraalkylammonium salts to the choliniumbased salts, as expected given the presence of the hydroxyl group in the cholinium cation. However, the association energy of the [ $\left.\mathrm{N}_{1111}\right]-$ based salts was lower than the remaining counterparts. Although the first member of the series is typically an outlier in terms of the association parameters, a higher association energy was expected, but the use of aqueous solutions data to obtain the parameters, and the consequent simultaneous fitting of a binary interaction parameter, may partly explain this result, as the $k_{i j}$ values applied decrease with the salt molecular weight, increasing the magnitude of the dispersive attractive interactions for the $\left[\mathrm{N}_{1111}\right]$-based salts. Although dispersion and associative interactions are accounted by different terms in the SAFT model, they are not isolated from each other, with some dispersivelike interactions masking part of the associative behavior of a compound.

Following the methodology presented in Section 3.1, the experimental solubilities of the different salts in water were modelled using the PC-SAFT EoS. The PC-SAFT parameters reported in Table 3 were then used to predict the solubilities in water. The results of such predictions are shown in Figs. 8 to 10 and demonstrate the capability of PC-SAFT to accurately predict the solubilities of some of the studied salts in water, namely $\left[\mathrm{N}_{2222}\right] \mathrm{Br},[\mathrm{Ch}] \mathrm{Br},\left[\mathrm{N}_{1111}\right] \mathrm{Cl}$ and $\left[\mathrm{N}_{2222}\right] \mathrm{Cl}$ (for $T>308 \mathrm{~K}$ ). However, as the chain length of the alkyl residues of the cation is increased, larger deviations from the experimental data are observed and a quantitative description of the data cannot be achieved. This is somehow expected considering that aqueous systems are still very challenging for most current thermodynamic models, hindering the calculation of different types of phase equilibria, or thermophysical properties, using the same set of parameters. Moreover, the binary interaction parameters between the different salts and water were regressed from the experimental densities and water activity coefficient data and are here applied to predict the temperature and compositional dependency of the salt activity coefficient, which is the other component of the system.

Hence, in order to achieve a quantitative agreement with the experimental data measured for all the studied systems, the binary interaction parameter $\left(k_{i j}\right)$ correcting the magnitude of the dispersive interactions between the salt and the solvent, was refitted. Obviously, a poor initial prediction, results in a greater readjustment of the binary parameter. The results of such procedure are shown in Fig. 8 to Fig. 10, while the refitted binary interaction parameters and deviations from the experimental data are reported in Table 4. To provide a more complete picture in terms of the capability to predict the solubilities. The salt aqueous solubilities calculated by COSMO-RS are also included in the same figures.

As can be observed in Figs. 8 to 10, by refitting the binary interaction parameter between the salt and water, an excellent description of the experimental solubility data can be achieved for all the studied systems without using temperature-dependent parameters. In what concerns the predictions with COSMO-RS, these are only satisfactory for the bromide salts providing a poor description of all chloride salts. This was somehow expected as it has been shown that COSMO-RS presents serious difficulties describing ion interactions, particularly those for small and highly charged ions like chloride [77]. Contributing to overcome this problem Gerlach et al. [78] combined COSMO-RS with a Pitzer-Debye-Hückel term to account for long-range electrostatic interactions between the ions obtaining very satisfactory results in the description of the mean ionic activity coefficients of the salts, and both liquid-liquid and vapor-liquid equilibrium of systems containing ions. 

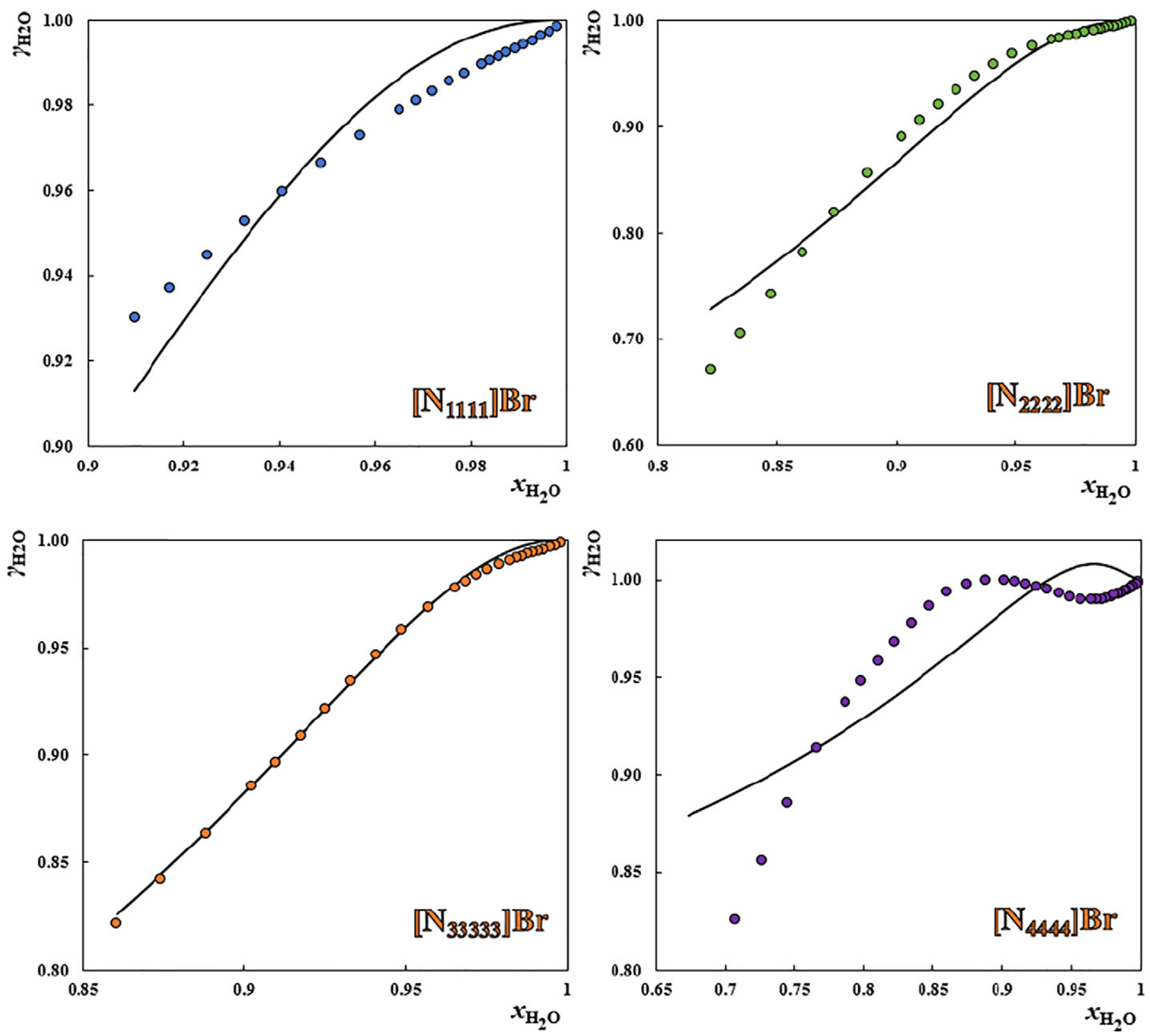

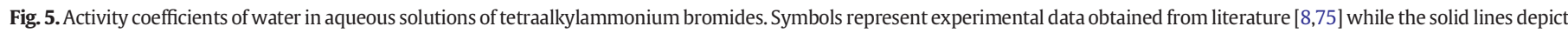
the PC-SAFT results.

\subsection{Melting enthalpies estimation}

Once the thermodynamic model proposed is able to reasonably describe different properties, in particular activity coefficients, as well as solubility data, it may also be used to estimate the unknown melting enthalpies of the salts. That is, the model can be used to calculate the activity coefficients of the salt at each experimental point $(T, x)$ and after, using a linearized form of Eq. (2), the melting enthalpy can be estimated. The results of such procedure using both the PC-SAFT, with the binary interaction parameters fitted to the solubility data, and using the COSMO-RS model are given in Table 5. When available, the results are compared with those reported in the literature.
Excepting three bromide salts, the COSMO-RS solubility predictions are unsatisfactory, that is, the change of the salt activity coefficients with temperature and composition are poorly described. This is shown again in Table 5 where for choline bromide, $\left[\mathrm{N}_{2222}\right] \mathrm{Br}$ or $\left[\mathrm{N}_{4444}\right] \mathrm{Br}$ the melting enthalpies estimated using COSMO-RS are quite close to the corresponding values estimated by PC-SAFT. This also supports the estimated enthalpies by PC-SAFT which present very acceptable magnitudes noting that, for instance, COSMO-RS estimate for the enthalpy of melting of $\left[\mathrm{N}_{4444}\right] \mathrm{Cl}$ a value of $103.19 \mathrm{~kJ} / \mathrm{mol}$, while PC-SAFT estimate is $26.52 \mathrm{~kJ} / \mathrm{mol}$, where other estimation procedure or calorimetric experimental datum indicates values close to $20 \mathrm{~kJ} / \mathrm{mol}$. Another relevant observation is that generally the melting enthalpies estimated by PC-SAFT for all bromide salts are lower than for the chlorides, in the opposite 

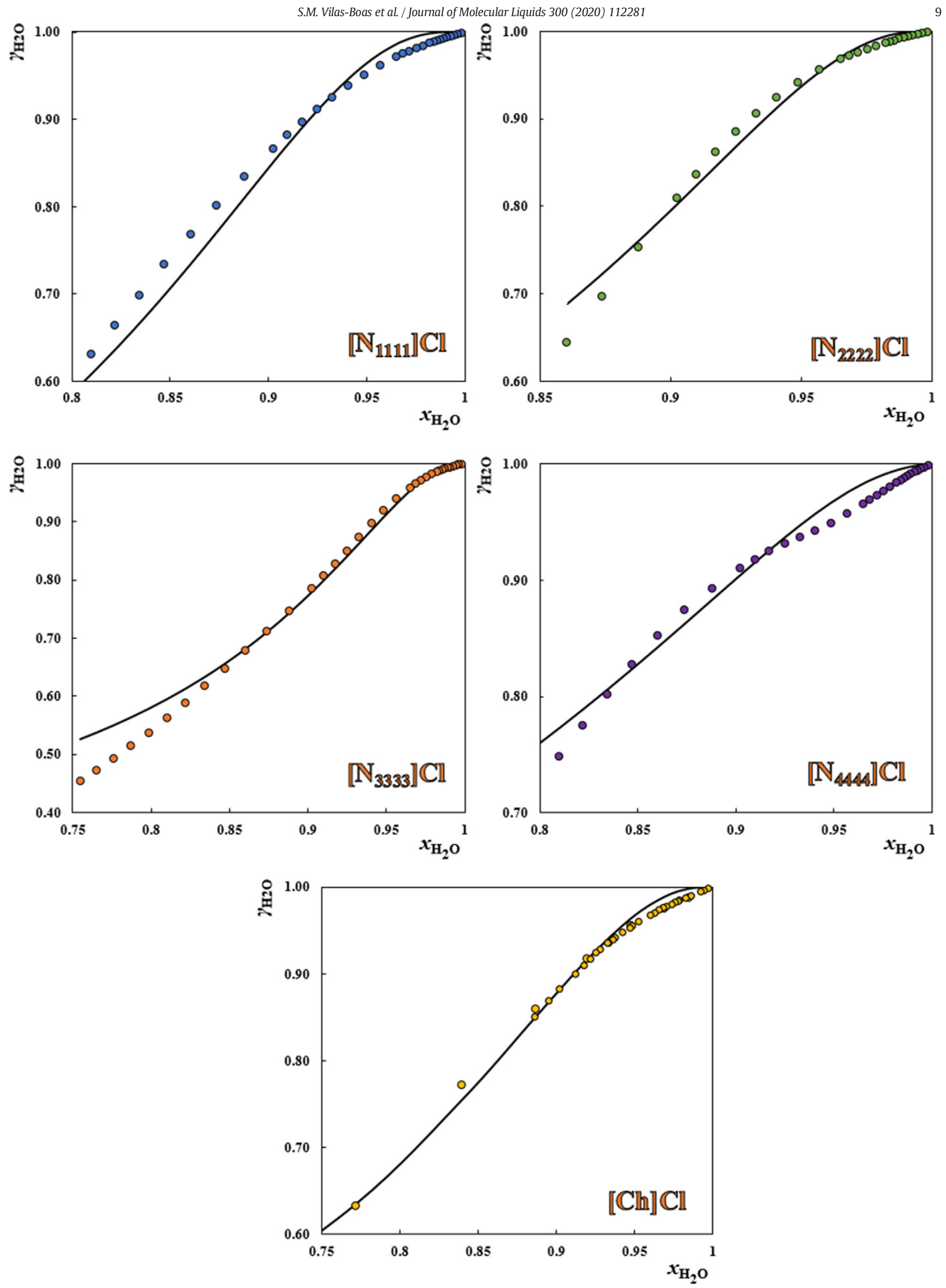
Table 3

PC-SAFT parameters proposed in this work for tetraalkylammonium salts and deviations from the experimental data used in the fitting.

\begin{tabular}{|c|c|c|c|c|c|c|c|c|}
\hline Salt & $m_{i}^{\text {seg }}$ & $\sigma_{i} / \AA$ & $u_{i i} / k_{B} \cdot K^{-1}$ & $\varepsilon^{A i B i} / K$ & $\kappa^{A i B i}$ & $k_{\text {salt-water }}$ & $\% A A R D(\rho)$ & $\% A A R D\left(\gamma_{w}\right)$ \\
\hline$\left[\mathrm{N}_{1111}\right] \mathrm{Br}$ & 10.270 & 2.518 & 267.33 & 1235 & 0.02 & -0.095 & 0.125 & 0.66 \\
\hline$\left[\mathrm{N}_{2222}\right] \mathrm{Br}$ & 14.130 & 2.574 & 271.00 & 2750 & 0.02 & -0.086 & 0.161 & 1.13 \\
\hline$\left[\mathrm{N}_{3333}\right] \mathrm{Br}$ & 17.890 & 2.675 & 284.99 & 2750 & 0.02 & -0.075 & 0.322 & 0.24 \\
\hline$\left[\mathrm{N}_{4444}\right] \mathrm{Br}$ & 21.540 & 2.753 & 294.05 & 2750 & 0.02 & -0.057 & 0.483 & 2.31 \\
\hline$[\mathrm{Ch}] \mathrm{Br}$ & 12.310 & 2.508 & 299.74 & 6765 & 0.02 & 0 & 0.464 & - \\
\hline$\left[\mathrm{N}_{1111}\right] \mathrm{Cl}$ & 13.050 & 2.290 & 289.75 & 1750 & 0.02 & -0.112 & 0.364 & 1.62 \\
\hline$\left[\mathrm{N}_{2222}\right] \mathrm{Cl}$ & 17.243 & 2.403 & 306.30 & 5000 & 0.02 & -0.101 & 0.259 & 1.16 \\
\hline$\left[\mathrm{N}_{3333}\right] \mathrm{Cl}$ & 21.800 & 2.509 & 312.02 & 5000 & 0.02 & -0.092 & 0.425 & 0.95 \\
\hline$\left[\mathrm{N}_{4444}\right] \mathrm{Cl}$ & 25.799 & 2.655 & 355.84 & 5000 & 0.02 & -0.051 & 0.545 & 1.07 \\
\hline$[\mathrm{Ch}] \mathrm{Cl}$ & 13.910 & 2.536 & 320.01 & 8000 & 0.02 & -0.156 & 0.279 & 1.01 \\
\hline
\end{tabular}

trend observed for the melting temperatures, and following a quite well-defined linear trend. Big differences are patent between experimental melting enthalpies values for $\left[\mathrm{N}_{2222}\right] \mathrm{Cl}$ and $\left[\mathrm{N}_{3333}\right] \mathrm{Cl}$ and those estimated by PC-SAFT, however like tetraalkylammonium salts, these compounds show degradation upon melting that could influence considerably the values obtained from the calorimetric measurements. In fact, the measurement of the melting properties of pure substances that decompose upon melting is quite difficult to perform, but very recently fast scanning calorimetry has been showing to be a promising technique. This has been primarily tested for low-molecular weight organic compounds [80] and very recently also tested to measure the melting properties of small peptides [81]. In this last work the activity and osmotic coefficients as well as densities in aqueous solutions were used to estimate PC-SAFT parameters, which were after combined with the measure melting properties to predict the solubility of the peptides in water showing very good agreement with the experimental observations. This procedure validates PC-SAFT both to predict solute activity coefficients at the saturation as well as the melting properties obtained by fast scanning calorimetry.

To the best of our knowledge this calorimetric technique has not yet been applied for salts, and no reliable melting enthalpy data are available for the alkylammonium salts studied in this work. Similarly to the work of Do et al. [81], the very good correlation results achieved in this work using PC-SAFT for the description of water activity coefficients, aqueous salt solution densities and solubility of the salt in water suggests the use of the PC-SAFT model to estimate the melting enthalpies of the studied salts. The values found are probably the best estimates to perform solid-liquid equilibrium studies, which are of utmost importance when designing and screening new (deep) eutectic mixtures.

\section{Conclusions}

In this work new solubility data of ten quaternary ammonium halides in water were measured in in the temperature range between $293.2 \mathrm{~K}$ and $348.2 \mathrm{~K}$ along with their densities at different molalities and temperatures. These new density data in aqueous solutions were combined with osmotic coefficients from the open literature to estimate the five PC-SAFT parameters representative of each compound. To the best of our knowledge this is the first set of parameters proposed for tetraalkylammonium salts in the framework of a SAFTtype EoS where all the expected trends for the non-associating parameters with the molecular weight are observed. These parameters were used to predict of the solubility data, but the description is not satisfactory as the mole fraction average absolute deviation is 0.018 , worsening with increasing alkyl chain length. If the PC-SAFT binary interaction parameter is re-estimated much better results are obtained $(A A D=0.0045)$. The well-known difficulties of COSMO-RS to describe systems containing ions was also confirmed since the solubility predictions achieved are quite unsatisfactory $(A A D=0.025)$, with poorer results for the chloride salts. After, PC-SAFT model was used to estimate the melting
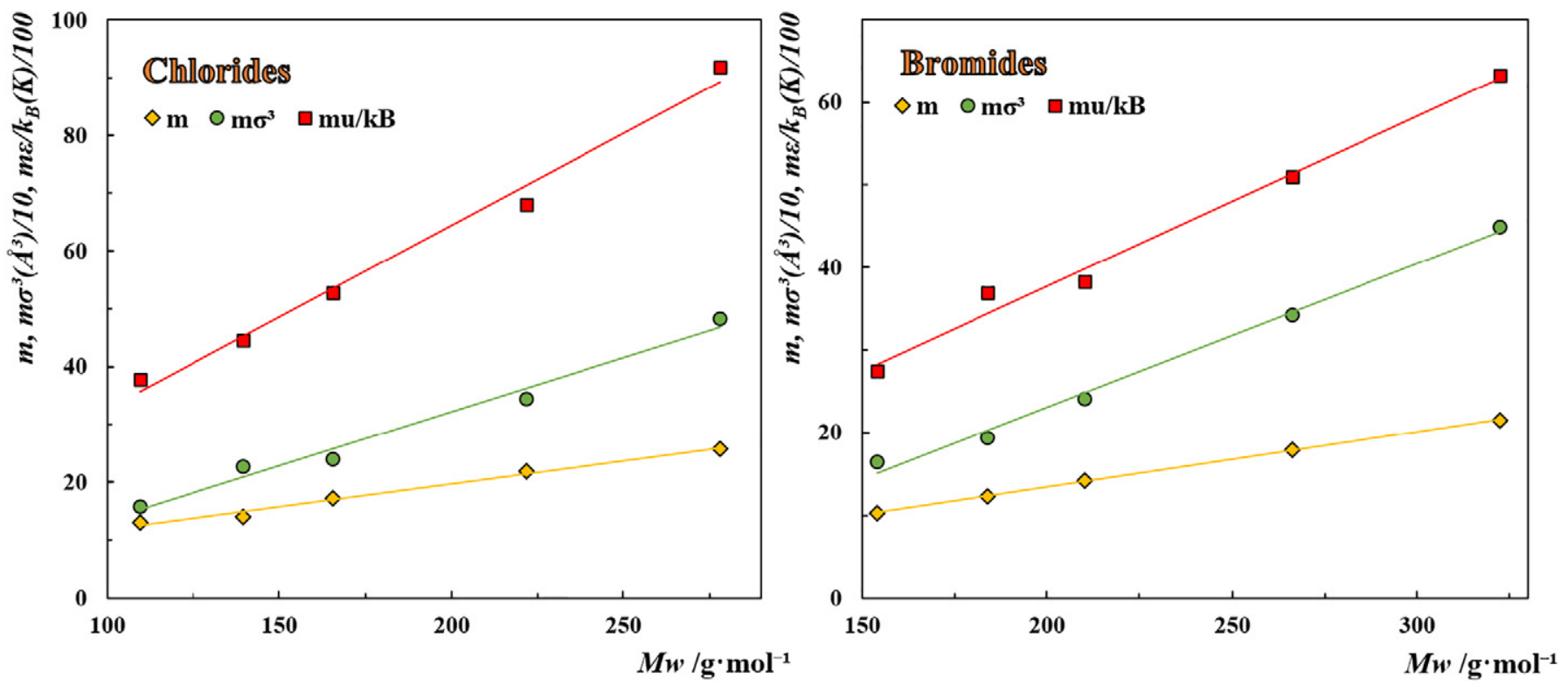

Fig. 7. Physical trends of the non-associating PC-SAFT parameters proposed in this work for tetraalkylammonium salts. 

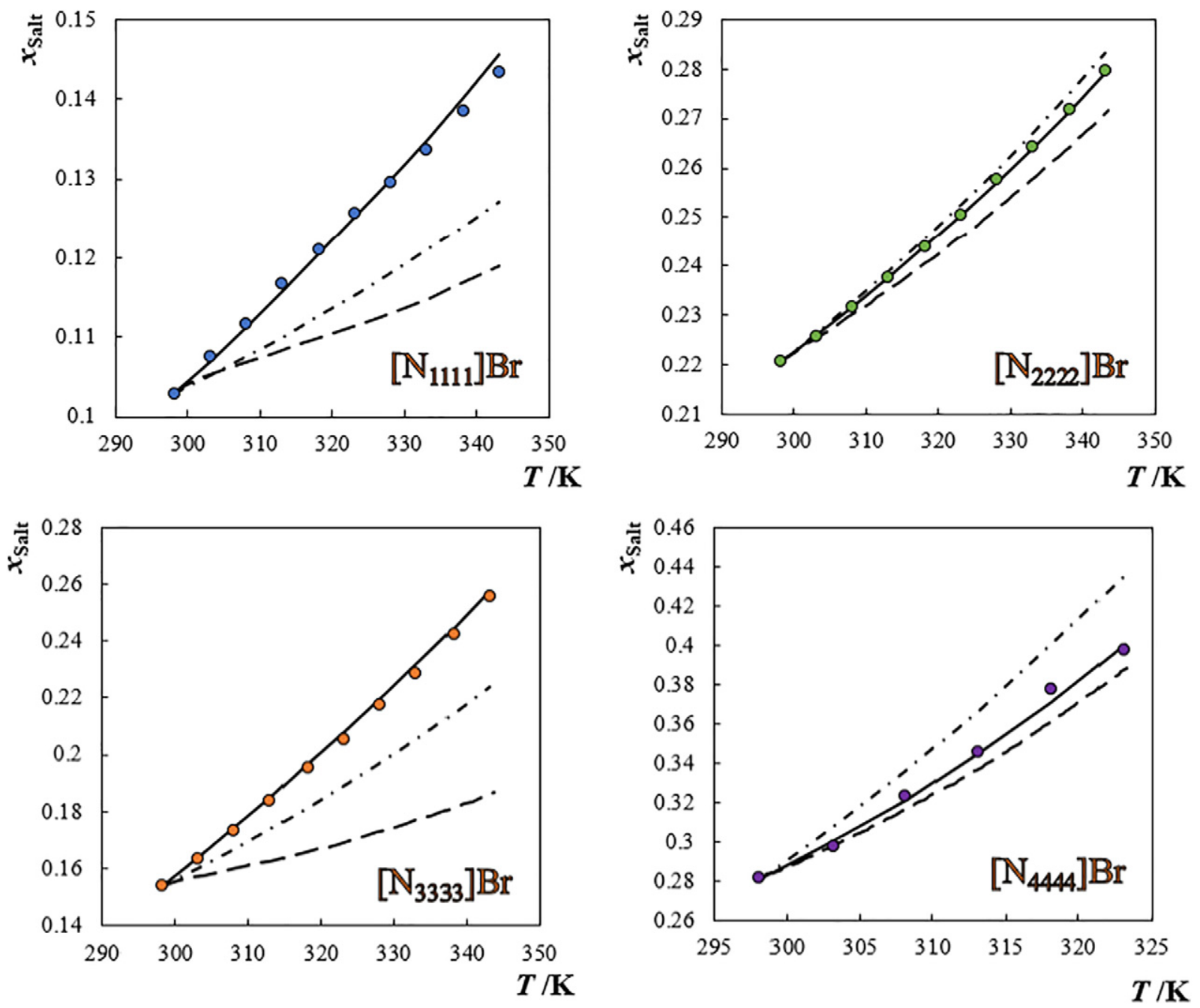

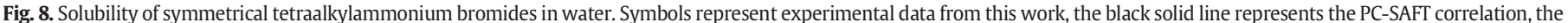
dot-dash line represents the PC-SAFT predictions and the long-dashed line represents the COSMO-RS prediction.

enthalpies of the quaternary alkylammonium halides by linear fit of the salt activity calculated by PC-SAFT with the reciprocal temperature. In spite of their uncertainty, the estimated melting enthalpies are possible

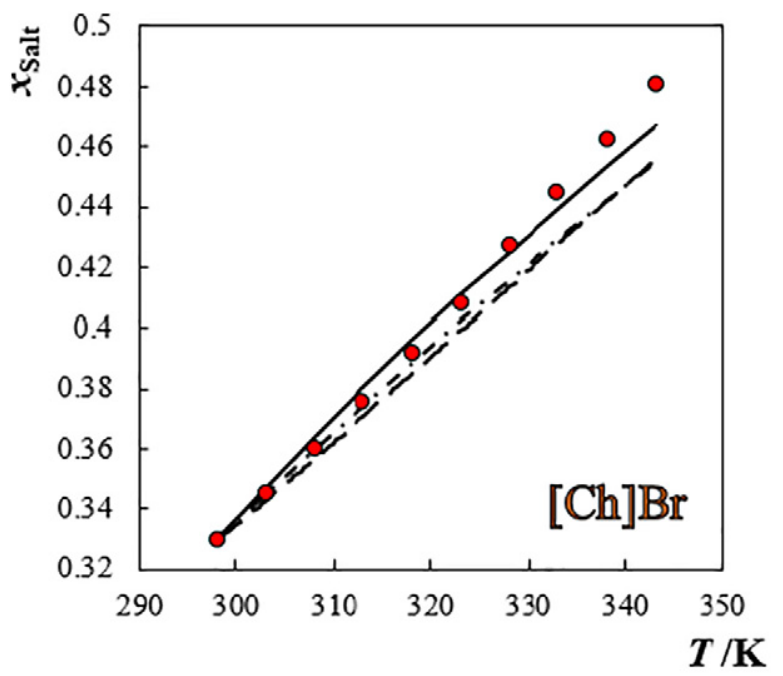

the best values to perform solid-liquid equilibrium analysis of utmost importance when designing and screening new deep eutectic mixtures based on these compounds.

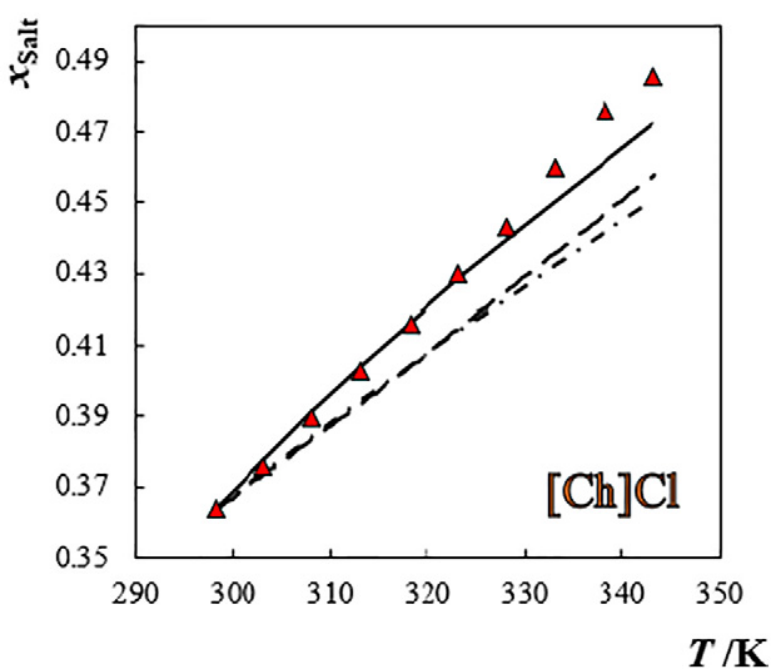

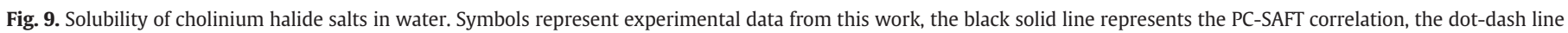
represents the PC-SAFT predictions and the long dashed line represents the COSMO-RS prediction. 

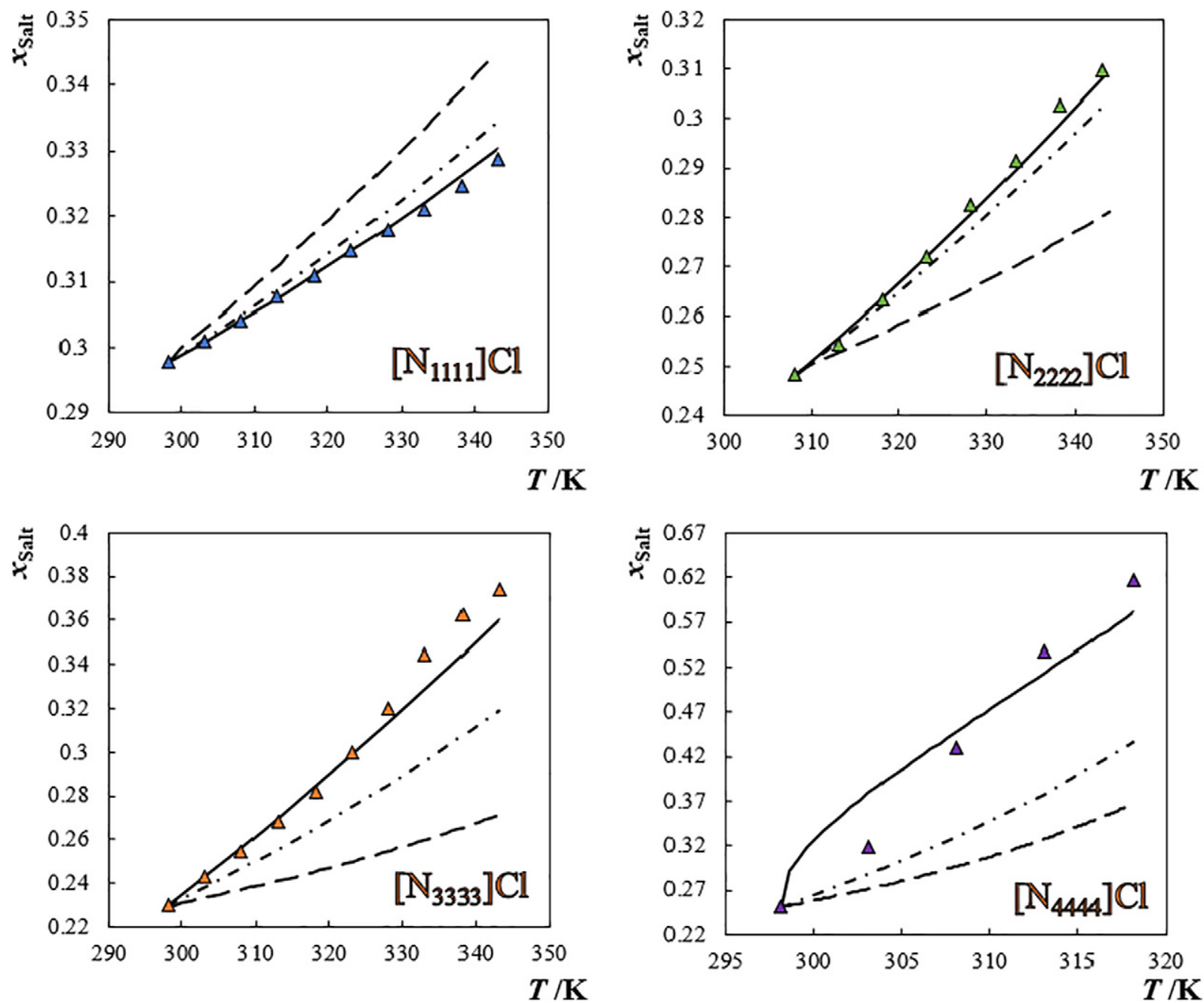

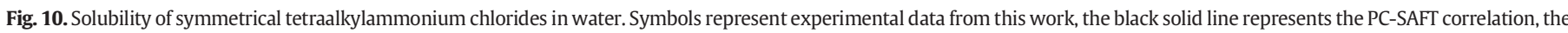
dot-dash line represents the PC-SAFT predictions and the long-dashed line represents the COSMO-RS prediction.

\section{Declaration of competing interests}

The authors declare that they have no known competing financial interests or personal relationships that could have appeared to influence the work reported in this paper.

\section{CRediT authorship contribution statement}

Sérgio M. Vilas-Boas:Investigation, Data curation, Writing - original draft.Dinis 0. Abranches:Investigation, Writing - original draft. Emanuel A. Crespo:Investigation, Writing - original draft.Olga

\section{Table 4}

Binary interaction parameters from Table 3 and those refitted to the experimental solubility data and the correspondent maximum absolute deviation (MAD) in terms of mole fraction from the experimental data.

\begin{tabular}{lllll}
\hline Salt & $k_{\text {salt-water }}$ & $M A D\left(x_{\text {SLE }}\right)$ & $k_{\text {salt-water }}$ & $M A D\left(x_{\text {SLE }}\right)$ \\
\hline$\left[\mathrm{N}_{1111}\right] \mathrm{Br}$ & -0.095 & 0.0163 & -0.048 & 0.0022 \\
{$\left[\mathrm{~N}_{2222}\right] \mathrm{Br}$} & -0.086 & 0.0036 & -0.096 & 0.0006 \\
{$\left[\mathrm{~N}_{3333}\right] \mathrm{Br}$} & -0.075 & 0.0317 & -0.045 & 0.0033 \\
{$\left[\mathrm{~N}_{4444}\right] \mathrm{Br}$} & -0.057 & 0.0383 & -0.120 & 0.0061 \\
{$[\mathrm{Ch}] \mathrm{Br}$} & 0 & 0.0252 & 0.010 & 0.0136 \\
{$\left[\mathrm{~N}_{1111}\right] \mathrm{Cl}$} & -0.112 & 0.0058 & -0.140 & 0.0016 \\
{$\left[\mathrm{~N}_{2222}\right] \mathrm{Cl}$} & -0.101 & 0.0087 & -0.085 & 0.0039 \\
{$\left[\mathrm{~N}_{3333}\right] \mathrm{Cl}$} & -0.092 & 0.0550 & -0.045 & 0.0181 \\
{$\left[\mathrm{~N}_{4444}\right] \mathrm{Cl}$} & -0.051 & 0.1809 & 0.057 & 0.0602 \\
{$[\mathrm{Ch}] \mathrm{Cl}$} & -0.156 & 0.0354 & -0.120 & 0.0146
\end{tabular}

Ferreira:Conceptualization, Supervision, Validation.João A.P. Coutinho:Conceptualization, Supervision, Writing - review \& editing. Simão P. Pinho:Conceptualization, Supervision, Validation, Writing review \& editing.

\section{Acknowledgments}

We acknowledge the support of the project “AIProcMat@N2020 Advanced Industrial Processes and Materials for a Sustainable Northern Region of Portugal 2020", with the reference NORTE-01-0145-FEDER-

Table 5

Enthalpies of melting $(\mathrm{kJ} / \mathrm{mol})$ estimated from the results obtained with PC-SAFT and COSMO-RS.

\begin{tabular}{llll}
\hline Salt & PC-SAFT & COSMO-RS & Literature \\
\hline$\left[\mathrm{N}_{1111}\right] \mathrm{Br}$ & 10.95 & 61.76 & - \\
{$\left[\mathrm{N}_{2222}\right] \mathrm{Br}$} & 13.43 & 15.80 & $20.08 \pm 0.40[9]^{\mathrm{a}}$ \\
{$\left[\mathrm{N}_{3333}\right] \mathrm{Br}$} & 12.06 & 38.24 & - \\
{$\left[\mathrm{N}_{4444}\right] \mathrm{Br}$} & 21.54 & 25.89 & $15.89 \pm 0.32[9]^{\mathrm{a}} ; 15.48 \pm 0.46[79]^{\mathrm{a}}$ \\
{$[\mathrm{Ch}] \mathrm{Br}$} & 6.52 & 6.75 & - \\
{$\left[\mathrm{N}_{1111}\right] \mathrm{Cl}$} & 12.03 & 8.47 & $20.49[7]^{\mathrm{a}}$ \\
{$\left[\mathrm{N}_{2222}\right] \mathrm{Cl}$} & 14.83 & 28.19 & $51.24 \pm 0.02[7]^{\mathrm{a}}$ \\
{$\left[\mathrm{N}_{3333}\right] \mathrm{Cl}$} & 12.41 & 39.03 & $66.58 \pm 2.10[7]^{\mathrm{a}}$ \\
{$\left[\mathrm{N}_{4444}\right] \mathrm{Cl}$} & 26.52 & 103.19 & $20.50 \pm 0.56[79]^{\mathrm{a}} ; 19.43[42]^{\mathrm{b}}$ \\
{$[\mathrm{Ch}] \mathrm{Cl}$} & 7.77 & 7.57 & $4.3 \pm 0.6[42]^{\mathrm{b}}$ \\
\hline
\end{tabular}

a Measured by DSC.

b Estimated from experimental solubility data. 
000006, supported by Norte Portugal Regional Operational Programme (NORTE 2020), under the Portugal 2020 Partnership Agreement, through the European Regional Development Fund (ERDF); Associate Laboratory LSRE-LCM - UID/EQU/50020/2019 - funded by national funds through FCT/MCTES (PIDDAC), the project CICECO - Aveiro Institute of Materials, FCT Ref. UID/CTM/50011/2019, financed by national funds through the FCT/MCTES; and project AllNat - POCI-01-0145FEDER-030463 (PTDC/EQU-EPQ/30463/2017), financed by FEDER funds through COMPETE and Portugal2020 and national funds through FCT Fundação para a Ciência e a Tecnologia. The FCT PhD. grants to S. M. Vilas-Boas (SFRH/BD/138149/2018) and E. A. Crespo (SFRH/BD/ 130870/2017) are also acknowledged.

\section{Appendix A. Supplementary data}

Tables S1 to S9 present the measured density data, while Table S10 present a list of the works used for comparison in Figs. S1 to S3. Tables S11 and S12 compiles the solubility data measured in this work and Table S13 compiles the solubility data available, at $298.2 \mathrm{~K}$ only. Finally, Fig. S4 compares the water activity coefficients in aqueous solutions of tetraalkylammonium bromides. The following are the supplementary data related to this article. Supplementary data to this article can be found online at https://doi.org/10.1016/j.molliq.2019. 112281.

\section{References}

[1] C. Zhang, F. Cui, G. Zeng, M. Jiang, Z. Yang, Z. Yu, M. Zhu, L. Shen, Quaternary ammonium compounds (QACs): a review on occurrence, fate and toxicity in the environment, Sci. Total Environ. 518-519 (2015) 352-362.

[2] M. Tischer, G. Pradel, K. Ohlsen, U. Holzgrabe, Quaternary ammonium salts and their antimicrobial potential: targets or nonspecific interactions? ChemMedChem 7 (2012) 22-31.

[3] B. Simoncic, B. Tomsic, Structures of novel antimicrobial agents for textiles - a review, Text. Res. J. 80 (2010) 1721-1737.

[4] A.P. Abbott, G. Capper, D.L. Davies, R. Rasheed, Ionic liquids based upon metal halide/substituted quaternary ammonium salt mixtures, Inorg. Chem. 43 (2004) 3447-3452.

[5] Q. Zhang, K. De Oliveira Vigier, S. Royer, F. Jérôme, Deep eutectic solvents: syntheses, properties and applications, Chem. Soc. Rev. 41 (2012) 7108-7146.

[6] E.L. Smith, A.P. Abbott, K.S. Ryder, Deep eutectic solvents (DESs) and their applications, Chem. Rev. 114 (2014) 11060-11082.

[7] P.V.A. Pontes, E.A. Crespo, M.A.R. Martins, L.P. Silva, C.M.S.S. Neves, G.J. Maximo, M.D Hubinger, E.A.C. Batista, S.P. Pinho, J.A.P. Coutinho, G. Sadowski, C. Held, Measurement and PC-SAFT modeling of solid-liquid equilibrium of deep eutectic solvent of quaternary ammonium chlorides and carboxylic acids, Fluid Phase Equilib. 448 (2017) 69-80.

[8] S. Lindenbaum, G.E. Boyd, Osmotic and activity coefficients for the symmetrica tetraalkyl ammonium halides in aqueous solution at $25^{\circ}$, J. Phys. Chem. 68 (1964) 911-917.

[9] J.A. Burns, R.E. Verrall, Thermodynamics of tetraalkyl-and bis-tetraalkylammonium bromides II. heat capacities of the solid state from 273 to $373 \& \mathrm{nbsp} ; \mathrm{K}$, Thermochim. Acta 9 (1974) 277-287.

[10] H. Nakayama, Solid-liquid and liquid-liquid phase equilibria in the symmetrical tetraalkylammonium halide-water systems, Bull. Chem. Soc. Jpn. 54 (1981) 3717-3722.

[11] J.W. M'David, Specific volume of solutions of tetra-propyl-ammonium chloride Proc. R. Soc. Edinburgh. 23 (1910) 515-520.

[12] M. Lucas, A. Feillolay, The enthalpy of solution of some molecules in aqueous tetraalkylammonium bromide solutions and the apparent expansion coefficient of the aqueous salt solution, J. Phys. Chem. 75 (1971) 2330-2335.

[13] W. Lin, D. Dalmazzone, W. Fürst, A. Delahaye, L. Fournaison, P. Clain, Thermodynamic studies of $\mathrm{CO} 2+\mathrm{TBAB}+$ water system: experimental measurements and correlations, J. Chem. Eng. Data 58 (2013) 2233-2239.

14] R. Golabiazar, R. Sadeghi, Salt-effects in aqueous surface-active ionic liquid 1 dodecyl-3- methylimidazolium bromide solutions: volumetric and compressibility property changes and critical aggregation concentration shifts, J. Chem. Thermodyn 76 (2014) 29-44.

[15] S. Chauhan, M. Kaur, D.S. Rana, M.S. Chauhan, Volumetric analysis of structura changes of cationic micelles in the presence of quaternary ammonium salts, J. Chem. Eng. Data 61 (2016) 3770-3778.

[16] W. Grzybkowski, D. Warmińska, Apparent molar volumes and isentropic compress ibilities of tetraalkylammonium bromides in aqueous propane-1,2-diol. An attempt to design hydraulic liquids, J. Chem. Eng. Data 61 (2016) 2933-2945.

[17] P.A. Tomar, V.R. Shaikh, K.J. Patil, Tetraalkylammonium bromide-water mixtures revisited: isothermal compressibility and internal pressure variation in limiting concentration range at $298.15 \mathrm{~K}$, J. Chem. Thermodyn. 126 (2018) 119-125.
[18] J. Doménech, J.M. Costa, Viscosity of tetraethylammonium bromide solutions in N,Ndimethylformamide-water mixtures, Electrochim. Acta 27 (1982) 1789-1793.

[19] K. Roy Choudhury, D.K. Majumdar, Viscocity of tetraethylammonium bromide and tetrabutylammonium bromide: high concentration range, Electrochim. Acta 29 (1984) 1371-1373.

[20] I.M.S. Lampreia, M.S.T. Neves, Limiting partial molar volumes and expansions for triethylamine in water and in aqueous tetraethylammonium chloride solutions from 15 to 35\&nbsp; ${ }^{\circ} \mathrm{C}$. J. Chem. Soc. Faraday Trans. 93 (1997) 2277-2281.

[21] Â.S. Mendonça, D.T.R. Formigo, I.M.S. Lampreia, Solubility of triethylamine in calcium chloride aqueous solutions from 20 to $35^{\circ} \mathrm{C}$, J. Solut. Chem. 31 (2002) 653-670.

[22] L.H. Blanco, E.F. Vargas, Apparent molar volumes of symetric and asymetric tetraalkylammonium salts in dilute aqueous solutions, J. Solut. Chem. 35 (2006) 21-28.

[23] T. Banerjee, N. Kishore, Interactions of peptides and lysozyme with aqueous tetraethylammonium bromide at 298.15 K, J. Solut. Chem. 35 (2006) 1389-1399.

[24] V. Belandria, A.H. Mohammadi, D. Richon, Volumetric properties of the (tetrahydrofuran + water) and (tetra- $\mathrm{n}$-butyl ammonium bromide + water) systems : experimental measurements and correlations, J. Chem. Thermodyn. 41 (2009) 1382-1386.

[25] S. Shaukat, R. Buchner, Densities, viscosities [from (278.15 to 318.15) K], and electrical conductivities (at $298.15 \mathrm{~K}$ ) of aqueous solutions of choline chloride and chlorocholine chloride, J. Chem. Eng. Data 56 (2011) 4944-4949.

[26] G. Jákli, K. Jerie, A. Baranowski, J. Glínski, Structure of aqueous solutions of tetramethylammonium chloride investigated by positron annihilation and ultrasonic methods, Acta Phys. Pol. A 93 (1998) 649-658.

[27] K. Jerie, A. Baranowski, G. Jákli, J. Glinski, Structure of aqueous solutions of tetraethylammonium chloride investigated by positron annihilation and ultrasonic methods, J. Radioanal. Nucl. Chem. 240 (1999) 223-229.

[28] G. Jákli, Tetrabutylammonium bromide aqueous solutions derived from density measurements †, J. Chem. Eng. Data 54 (2009) 2656-2665.

[29] G. Jákli, Thermal expansion and structure of tetrapropylammonium bromide aqueous solutions derived from density measurements, J. Chem. Thermodyn. 43 (2011) 284-289

[30] M. Francisco, A.S.B. González, S.L. García de Dios, W. Weggemans, M.C. Kroon, Comparison of a low transition temperature mixture (LTTM) formed by lactic acid and choline chloride with choline lactate ionic liquid and the choline chloride salt: physical properties and vapour-liquid equilibria of mixtures containing water and ethanol, RSC Adv. 3 (2013), 23553.

[31] B.J. Levien, Some physical properties of aqueous solutions of tetramethylammonium bromide and tetramethylammonium iodide, Aust. J. Chem. 18 (1965) 1161-1170.

[32] J.A. Burns, W.F. Furter, Effects of salts having large organic ions on vapor-liquid equilibrium, Adv. Chem. 155 (1976) 99-127.

[33] G. Jackson, W.G. Chapman, K.E. Gubbins, Phase equilibria of associating fluids of spherical and chain molecules, Int. J. Thermophys. 9 (1988) 769-779.

[34] W.G. Chapman, G. Jackson, K.E. Gubbins, Phase equilibria of associating fluids. Chain molecules with multiple bonding sites, Mol. Phys. 65 (1988) 1057-1079.

[35] W.G. Chapman, K.E. Gubbins, G. Jackson, M. Radosz, SAFT: equation-of-state solution model for associating fluids, Fluid Phase Equilib. 52 (1989) 31-38.

[36] W.G. Chapman, K.E. Gubbins, G. Jackson, M. Radosz, New reference equation of state for associating liquids, Ind. Eng. Chem. Res. 29 (1990) 1709-1721.

[37] L.F. Zubeir, C. Held, G. Sadowski, M.C. Kroon, PC-SAFT modeling of CO2 solubilities in deep eutectic solvents, J. Phys. Chem. B 120 (2016) 2300-2310.

[38] J.O. Lloret, L.F. Vega, F. Llovell, Accurate description of thermophysical properties of tetraalkylammonium chloride deep eutectic solvents with the soft-SAFT equation of state, Fluid Phase Equilib. 448 (2017) 81-93.

[39] J. Gross, G. Sadowski, Perturbed-chain SAFT: an equation of state based on a perturbation theory for chain molecules, Ind. Eng. Chem. Res. 40 (2001) 1244-1260.

[40] J. Gross, G. Sadowski, Application of the perturbed-chain SAFT equation of state to associating systems, Ind. Eng. Chem. Res. 41 (2002) 5510-5515.

[41] D.O. Abranches, L.P. Silva, M.A.R. Martins, L. Fernandez, S.P. Pinho, J.A.P. Coutinho, Can cholinium chloride form eutectic solvents with organic chloride-based salts? Fluid Phase Equilib. 493 (2019) 120-126.

[42] L. Fernandez, L.P. Silva, M.A.R. Martins, O. Ferreira, J. Ortega, S.P. Pinho, J.A.P. Coutinho, Indirect assessment of the fusion properties of choline chloride from solid-liquid equilibria data, Fluid Phase Equilib. 448 (2017) 9-14.

[43] ChemSpider, https://www.chemspider.com/, Accessed date: 30 August 2019 (n.d.).

[44] O. Ferreira, S. Pinho, Solubility of flavonoids in pure solvents, Ind. Eng. Chem. Res. 51 (2012) 6586-6590.

[45] J.M. Prausnitz, R.N. Lichtenthaler, E.G. de Azevedo, Molecular Thermodynamics of Fluid-Phase Equilibria, Pretnice Hall PTR, 1999.

[46] J.R. Elliott, C.T. Lira, Introductory Chemical Engineering Thermodynamics, Second edi, Prentice Hall PTR, 1999.

[47] M.A.R. Martins, S.P. Pinho, J.A.P. Coutinho, Insights into the nature of eutectic and deep eutectic mixtures, J. Solut. Chem. (2018) 1-21.

[48] M.S. Wertheim, Fluids with highly directional attractive forces. I. Statistical thermodynamics, J. Stat. Phys. 35 (1984) 19-35.

[49] M.S. Wertheim, Fluids with highly directional attractive forces. II.Thermodynamic perturbation theory and integral equations, J. Stat. Phys. 35 (1984) 35-47.

[50] M.S. Wertheim, Fluids with highly directional attractive forces. III. Multiple attraction sites, J. Stat. Phys. 42 (1986) 459-476.

[51] M.S. Wertheim, Fluids with highly directional attractive forces. IV. Equilibrium polymerization, J. Stat. Phys. 42 (1986) 477-492.

[52] J.A. Barker, D. Henderson, Perturbation theory and equation of state for fluids: the square-well potential, J. Chem. Phys. 47 (1967) 2856-2861. 
[53] J.A. Barker, D. Henderson, Perturbation theory and equation of state for fluids. II. A successful theory of liquids, J. Chem. Phys. 47 (1967) 4714-4721.

[54] J.P. Wolbach, S.I. Sandler, Using molecular orbital calculations to describe the phase behavior of cross-associating mixtures, Ind. Eng. Chem. Res. 37 (1998) 2917-2928.

[55] L.F. Cameretti, G. Sadowski, Modeling of aqueous amino acid and polypeptide solutions with PC-SAFT, Chem. Eng. Process. Process Intensif. 47 (2008) 1018-1025.

[56] X. Ji, C. Held, G. Sadowski, Modeling imidazolium-based ionic liquids with ePC-SAFT, Fluid Phase Equilib. 335 (2012) 64-73.

[57] A. Nann, J. Mündges, C. Held, S.P. Verevkin, G. Sadowski, Molecular interactions in 1butanol + IL solutions by measuring and modeling activity coefficients, J. Phys. Chem. B 117 (2013) 3173-3185.

[58] H. Passos, I. Khan, F. Mutelet, M.B. Oliveira, P.J. Carvalho, L.M.N.B.F. Santos, C. Held, G. Sadowski, M.G. Freire, J.A.P. Coutinho, Vapor-liquid equilibria of water + alkylimidazolium-based ionic liquids: measurements and perturbed-chain statistical associating fluid theory modeling, Ind. Eng. Chem. Res. 53 (2014) 3737-3748.

[59] S.H. Huang, M. Radosz, Equation of state for small, large, polydisperse and associating molecules, Ind. Eng. Chem. Res. 29 (1990) 2284-2294.

[60] T. Kraska, K.E. Gubbins, Phase equilibria calculations with a modified SAFT equation of state. 1. Pure alkanes, alkanols, and water, Ind. Eng. Chem. Res. 35 (1996) 4727-4737.

[61] F.J. Blas, L.F. Vega, Prediction of binary and ternary diagrams using the statistical associating fluid theory (SAFT) equation of state, Ind. Eng. Chem. Res. 37 (1998) 660-674.

[62] P. Navarro, E.A. Crespo, J.M.L. Costa, F. Llovell, J. García, F. Rodríguez, P.J. Carvalho, L.F. Vega, J.A.P. Coutinho, New experimental data and modeling of glymes: toward the development of a predictive model for polyethers, Ind. Eng. Chem. Res. 56 (2017) 7830-7844.

[63] R.M. Ojeda, F. Llovell, Soft-SAFT transferable molecular models for the description of gas solubility in eutectic ammonium salt-based solvents, J. Chem. Eng. Data 63 (2018) 2599-2612.

[64] I. Khan, K.A. Kurnia, T.E. Sintra, J.A. Saraiva, S.P. Pinho, J.A.P. Coutinho, Assessing the activity coefficients of water in cholinium-based ionic liquids: experimental measurements and COSMO-RS modeling, Fluid Phase Equilib. 361 (2014) 16-22.

[65] A. Klamt, Conductor-like screening model for real solvents: a new approach to the quantitative calculation of solvation phenomena, J. Phys. Chem. 99 (1995) 2224-2235.

[66] A. Klamt, V. Jonas, T. Bürger, J.C.W. Lohrenz, Refinement and parametrization of COSMO-RS, J. Phys. Chem. A 102 (1998) 5074-5085.

[67] TURBOMOLE V7.1 2016, http://www.turbomole.com (n.d.)

[68] A.M. Cezaro, J.P. Bender, M.L. Corazza, C. Steffens, M.V. Tres, J.V. Oliveira, Phase equilibrium data for ternary ( carbon dioxide + dichloromethane + eugenol $)$ and quaternary systems ( carbon dioxide + dichloromethane + eugenol + poly- e -caprolactone ), Jounal Chem. Thermodyn. 91 (2015) 336-345.

[69] L.P. Silva, L. Fernandez, J.H.F. Conceiçao, M.A.R. Martins, A. Sosa, J. Ortega, S.P. Pinho, J.A.P. Coutinho, Design and characterization of sugar-based deep eutectic solvents using Conductor-like Screening Model for Real Solvents, ACS Sustain. Chem. Eng. 6 (2018) 10724-10734.

[70] D.O. Abranches, M. Larriba, L.P. Silva, M. Melle-Franco, J.F. Palomar, S.P. Pinho, J.A.P. Coutinho, Using COSMO-RS to design choline chloride pharmaceutical eutectic solvents, Fluid Phase Equilib. 497 (2019) 71-78.

[71] A. Klamt, F. Eckert, W. Arlt, COSMO-RS: an alternative to simulation for calculating thermodynamic properties of liquid mixtures, Annu. Rev. Chem. Biomol. Eng. 1 (2010) 101-122.

[72] COSMOtherm, C3.0 release 17.01, http://www.cosmologic.de.

[73] F. Eckert, A. Klamt, Fast solvent screening via quantum chemistry: COSMO-RS approach, AICHE J. 48 (2002) 369-385.

[74] K.D. Collins, G.W. Neilson, J.E. Enderby, Ions in water: characterizing the forces that control chemical processes and biological structure, Biophys. Chem. 128 (2007) 95-104.

[75] E. Amado G, L.H. Blanco, Isopiestic determination of the osmotic and activity coefficients of dilute aqueous solutions of symmetrical and unsymmetrical quaternary ammonium bromides with a new isopiestic cell at 298.15 K, Fluid Phase Equilib. 233 (2005) 230-233.

[76] J.B. Macaskill, M.S. Mohan, R.G. Bates, Activity coefficients and osmotic coefficients in aqueous solutions of choline chloride at $25^{\circ} \mathrm{C}$, Anal. Chem. 49 (1977) 209-212.

[77] M. Diedenhofen, A. Klamt, COSMO-RS as a tool for property prediction of IL mixtures - a review, Fluid Phase Equilib. 294 (2010) 31-38.

[78] T. Gerlach, S. Müller, I. Smirnova, Development of a COSMO-RS based model for the calculation of phase equilibria in electrolyte systems, AICHE J. 64 (2018) 272-285.

[79] T.G. Coker, J. Ambrose, G.J. Janz, Fusion properties of some ionic quaternary ammonium compounds, J. Am. Chem. Soc. 92 (1970) 5293-5297.

[80] M.I. Yagofarov, S.E. Lapuk, T.A. Mukhametzyanov, M.A. Ziganshin, C. Schick, B.N. Solomonov, Application of fast scanning calorimetry to the fusion thermochemistry of low-molecular-weight organic compounds: fast-crystallizing m-terphenyl heat capacities in a deeply supercooled liquid state, Thermochim. Acta 668 (2018) 96-102.

[81] H.T. Do, Y.Z. Chua, J. Habicht, M. Klinksiek, M. Hallermann, D. Zaitsau, C. Schick, C. Held, Melting properties of peptides and their solubility in water. Part 1: dipeptides based on glycine or alanine, RSC Adv. 9 (2019) 32722-32734. 